\title{
Analisis Perubahan Persepsi Jamaah Dakwah Ustadz Evie Effendi Di Kota Bandung
}

\author{
Nadhillah Kusindriani $^{1} *$, Martha Tri Lestari ${ }^{2}$ \\ 1 Telkom University, Indonesia \\ 2 Telkom University, Indonesia \\ *dbilanadbillab@gmail.com
}

\begin{abstract}
Ustadz. Evie Effendi was a public figure who is known by the public as a modern ustadz that use the Sundanese language when do Da'wah. The perceptions given by the society particularly of ustadz Evie Effendi Da'wah pilgrims are positive until ultimately ustadz. Evie exposed "misinterpretation" case in August 2018 when he misinterpreted a verse in the Sura in the Quran. The occurrence of a case of "misinterpretation" had a significant impact for ustadz Evie Effendi, one of them is a lot of pilgrims from ustadz. Evie Effendi in Bandung which is no longer a loyal following lectures activities conducted by him. The existence of the impact that occurs from the "misinterpretation" case encourages researchers to see how the changes in perception that occurred in ustadz. Evie Effendi Da'wah worshipers in Bandung. This study used a qualitative approach through the case study method uses the concept of Yin (2015). The results of this research show that changes in perception that occurred in Ustadz Evie Effendi Da'wah worshipers in Bandung is different for adult ages (40 - 50 years) and adolescents (20 years) as well as temporary caused culture society Indonesia which is permissive.
\end{abstract}

Keywords : Da'wah; changes in perception; "misinterpretation" case; qualitative.

\begin{abstract}
ABSTRAK
Ustadz Evie Effendi merupakan seorang publik figur yang dikenal oleh masyarakat sebagai ustadz kekinian yang menggunakan bahasa Sunda ketika ceramah. Persepsi yang diberikan masyarakat khususnya jamaah dakwah ustadz Evie Effendi positif sampai pada akhirnya ustadz Evie terkena kasus "salah tafsir" pada bulan Agustus 2018 ketika ia salah menfasirkan ayat dalam suatu surat di Al-Quran. Terjadinya kasus "salah tafsir" memberikan dampak yang cukup besar bagi ustadz Evie Effendi salah satunya adalah banyak dari jamaah dakwah ustadz Evie Effendi di Kota Bandung yang tidak lagi setia mengikuti kegiatan ceramah yang dilakukan ustadz Evie Effendi. Adanya dampak yang terjadi dari kasus "salah tafsir" mendorong peneliti untuk melihat bagaimana perubahan persepsi yang terjadi pada jamaah dakwah ustadz Evie Effendi di Kota Bandung. Penelitian ini menggunakan pendekatan kualitatif melalui metode studi kasus menggunakan konsep Yin (2015). Hasil penelitian ini menunjukkan bahwa perubahan persepsi yang terjadi pada jamaah dakwah ustadz Evie Effendi di Kota Bandung berbeda untuk kalangan usia dewasa (40 - 50 tahun) dan remaja (20 tahun) serta
\end{abstract}

Diterima: Februari 2019. Disetujui: April 2019. Dipublikasikan: Juni 2019

50 
bersifat sementara yang disebabkan kultur masyarakat Indonesia yang permisif.

Kata kunci: Ceramah; perubahan persepsi; kasus "salah tafsir"; kualitatif.

\section{PENDAHULUAN}

Ustadz Evie Effendi merupakan salah satu ustadz yang digemari oleh masyarakat Kota Bandung dan dikenal sebagai ustadz gaul oleh semua kalangan masyarakat, mulai dari anak muda hingga orang tua. Ustadz Evie Effendi yang dikenal dengan slogan "Jangan Lupa Bahagia" tersebut menarik perhatian masyarakat dalam kajian ceramahnya yang unik yaitu mencampurkan bahasa Indonesia dengan bahasa Sunda kasar dalam ceramahnya, menyelipkan lelucon yang menjadi tren dan disukai oleh semua kalangan dengan memakai bahasa Sunda yang memicu gelak tawa dari jamaahnya. Selain itu, cara berpakain ustadz Evie yang berbeda dari ustadz-ustadz pada umumya, yaitu menggunakan topi kupluk, celana jeans, kaos dibalut kemeja dengan kancing terbuka dan jaket ketika ceramah. Ustadz Evie Effendi juga mampu mengajak anak pinggiran dan anak punk di Kota Bandung hijrah dengan membangun komunitas MTI. Keunikan-keunikan tersebut yang membuat masyarakat khususnya jamaah dakwah ustadz Evie di Kota Bandung memiliki persepsi positif pada ustadz Evie Effendi.

Persepsi positif pada ustadz Evie Effendi terus berkembang di masyarakat hingga pada bulan Agustus 2018 ustadz Evie tersangkut kasus "salah tafsir" ayat Al-Quran yaitu surat Ad-Dhuha ayat 7 perihal Nabi Muhammad SAW. Kasus "salah tafsir" terjadi disebabkan oleh tersebarnya penggalan video ceramah ustadz Evie Effendi di Youtube yang mengatakan bahwa "Semua orang yang ada di permukaan bumi ini pernah sesat termasuk Muhammad. Jadi, orang yang memperingati maulid berarti memperingati kesesatan Muhammad”. Kalimat yang dilontarkan oleh ustadz Evie Effendi pada video tersebut memicu amarah beberapa pihak baik masyarakat maupun organisasi Islam hingga mengambil sikap dan langkah tegas dalam menanggapi hal tersebut. Salah satunya adalah IPNU (Ikatan Pelajar Nahdlatul Ulama) Jawa Barat yang melaporkan ustadz Evie Effendi ke Polda Jabar atas dugaan pelanggaran Undang-Undang Informasi dan Transaksi Elektronik (UU ITE) per tanggal 11 Agustus 2018 dengan nomor laporan UU ITE LPB/769/VIII/2018/JABAR atas nama pelapor Hasan Malawi selaku wakil ketua Bidang Kaderisasi IPNU Jabar. Berita mengenai kasus salah tafsir surat Ad-Dhuha sudah beredar luas di portal berita online seperti jawa pos, liputan6.com, detik.com dan lainnya.

Terkait kasus "salah tafsir", ustadz Evie Effendi sudah meminta maaf dan mengklarifikasi melalui video yang di unggah di official Youtube ustadz Evie Effendi. Beliau membenarkan adanya video ceramah yang beredar di Youtube 
dan beliau juga mengatakan bahwa ceramah pada video tersebut sudah terjadi sejak bulan Februari 2018 ketika ustadz Evie ceramah di daerah Cileunyi, Bandung namun baru dijadikan masalah dan diangkat ke media bulan Agustus 2018. Terjadimya kasus "salah tafsir" ini memberikan dampak yang cukup besar kepada masyarakat dan orang-orang di sekitar beliau, diantaranya manajemen ustadz Evie Effendi bubar, jadwal kajian menjadi berantakan hingga banyak dari jamaah dakwah beliau yang memutuskan untuk balik kanan atau tidak lagi setia mendengarkan dan mengikuti kajian yang dilakukan oleh ustadz Evie Effendi, hingga pada dampak jangka panjangnya yaitu beliau membatalkan semua jadwal kajian di masjid-masjid Kota Bandung maupun daerah-daerah lainnya untuk beberapa bulan ke depan serta diperkuat dengan hilangnya media sosial Instagram ustadz Evie Effendi yang digunakan sebagai media untuk memberikan informasi jadwal ceramah beliau. Data terkait dampak-dampak yang terjadi setelah adanya kasus "salah tafsir" ustadz Evie Effendi peneliti dapatkan dari hasil pra reset melalui wawancara dengan kepala Humas Masjid Trans Studio Bandung.

Kasus "salah tafsir" ustadz Evie Effendi tergolong kasus baru yang menjerat ustadz Evie dan menjadi perbincangan masyarakat karena terangkat oleh media dan disajikan secara terus-menerus. Kasus "salah tafsir" ini menjerat ustadz Evie Effendi ketika ia sedang berada pada puncak kejayaan dakwahnya, menggemparkan masyarakat khususnya jamaah dakwah beliau di Kota Bandung dan secara tidak langsung menarik perhatian serta mengubah persepsi masyarakat dan jamaah dakwahnya. Persepsi pada dasarnya menurut Deddy Mulyana merupakan inti dari sebuah proses komunikasi karena persepsi merupakan suatu proses yang di dahului oleh proses penginderaan, yaitu merupakan proses diterimanya stimulus oleh individu melalui alat indera. Persepsi dapat didefinisikan sebagai suatu kemampuan yang dimiliki manusia untuk membedakan, mengelompokkan, kemudian memfokuskan pikiran kepada suatu hal untuk menginterpretasikannya. Rakhmat melihat bahwa persepsi yang diberikan setiap individu berbeda hal tersebut ditentukan oleh faktor-faktor yang menentukan persepsi, diantaranya perhatian yang terbagi menjadi faktor eksternal penarik perhatian dan faktor internal penaruh perhatian, faktor-faktor fungsional yang menentukan persepsi dan faktor-faktor struktural yang menentukan persepsi (Rakhmat, 2011:51-52).

Persepsi dalam komunikasi dakwah pun sama dimana komunikan (mad'u) menginterpretasikan stimulus atau kesan-kesan sensoris berupa pesan-pesan dakwah yang disampaikan komunikator (dai) dan diterima melalui alat indera mad'u. Dalam hal ini pesan yang disampaikan berupa pesan dakwah dimana dai memberikan informasi sekaligus mempersuasi komunikannya (mad'u) untuk melakukan suatu perubahan ke arah yang positif, baik perubahan dalam bentuk 
pola pikir, cara pandang terhadap suatu hal maupun perubahan sikap dan tingkah laku. Bahasa menjadi salah satu faktor penentu kegiatan komunikasi berjalan dengan baik. Bahasa pada dasarnya merupakan alat atau media yang menjadi faktor penting dalam berlangsungnya kegiatan komunikasi, dimana komunikasi menurut Mary B. Cassata dan Molefi K. Asante (dalam Mulyana, 2017:69) merupakan proses transmisi informasi yang bertujuan mempengaruhi khalayak. Jika khalayak sudah terpengaruh dengan informasi yang diberikan maka mulai terbentuk pandangan terhadap informasi tersebut dan komunikatornya (pemberi pesan).

Kegiatan komunikasi yang dilakukan ustadz Evie Effendi terlihat sudah sangat baik, hal tersebut dibuktikan dengan banyaknya masyarakat khususnya di Kota Bandung yang menyukai ustadz Evie Effendi sehingga terbentuk persepsi positif terhadap beliau di masyarakat khususnya jamaah dakwah di Kota Bandung. Namun semenjak adanya kasus "salah tafsir" banyak dampak yang terjadi sesuai dengan pemaparan peneliti sebelumnya. Maka dari itu, berdasarkan data yang di dapat peneliti ingin mengetahui lebih jauh apakah dampak tersebut terjadi karena adanya perubahan persepsi dari masyarakat khususnya jamaah dakwah beliau dan peneliti tertarik untuk meneliti tentang "Analisis Perubahan Persepsi Jamaah Dakwah Ustadz Evie Effendi di Kota Bandung (Studi Kasus "Salah Tafsir" Ustadz Evie Effendi)".

Adapun penelitian-penelitian terdahulu yang terkait dan serupa dengan penelitian peneliti diantaranya sebagai berikut:

Tabel 1. Penelitian Terdahulu

\section{Penelitian Terdahulu}

\begin{tabular}{lllll}
\hline Skripsi & Persepsi & Persepsi Calon & Persepsi & Persepsi \\
& Mahasiswa & Jamaah Haji & Masyarakat & Jamaah \\
IMARAH & Terhadap Akad & Tentang & Terhadap \\
Terhadap & dalam Dana & Aktualitas & Penggunaan \\
Dakwah & Setoran Awal & Informasi & Parabahasa \\
Ustadz Azhar & Pelaksanaan Haji & Berita di TV & dan Gerakan \\
Idrus di Media & (Studi Kasus & One (Studi & Tangan \\
Youtube & Kementerian & Pada & Dalam \\
& (Sailan, 2017) & Agama Kota & Masyarakat & Dakwah \\
& Banjarmasin) & Allattappamp & Habib \\
& (Adib,S.,2017) & Pallangga & Muhammad \\
& & Gowa)(Azis, & Firdaus \\
& & F, 2016) & (Studi Kasus \\
& & & Jamaah Al- \\
\hline
\end{tabular}




\begin{tabular}{|c|c|c|c|c|}
\hline & & & & $\begin{array}{l}\text { Muqorrobin } \\
\text { Kendal)(Fatk } \\
\text { hiyyah, 2017) }\end{array}$ \\
\hline $\begin{array}{l}\text { Jurnal } \\
\text { Nasional }\end{array}$ & $\begin{array}{l}\text { Penelitian } \\
\text { Studi Kasus } \\
\text { Fenomenologi } \\
\text { Persepsi } \\
\text { Keadilan } \\
\text { Pelaku } \\
\text { Pembunuhan } \\
\text { Anggota PKI } \\
\text { 1965(Pambudi, } \\
\text { K.S., 2017). }\end{array}$ & $\begin{array}{l}\text { Persepsi } \\
\text { Masyarakat DKI } \\
\text { Jakarta Terhadap } \\
\text { Figur dan } \\
\text { Komunikasi } \\
\text { Politik Basuki } \\
\text { Tjahaja Purnama } \\
\text { (AHOK) } \\
\text { (Prasetyo, } \\
\text { D.(2014) }\end{array}$ & $\begin{array}{l}\text { Persepsi } \\
\text { Jamaah } \\
\text { Terhadap } \\
\text { Pemberdayaa } \\
\text { n oleh Takmir } \\
\text { Masjid di } \\
\text { Kota Madiun } \\
\text { Jawa Timur } \\
\text { Rosidin, } \\
\text { 2018) }\end{array}$ & $\begin{array}{l}\text { Persepsi } \\
\text { Masyarakat } \\
\text { Terhadap } \\
\text { Kebijakan } \\
\text { Ekonomi } \\
\text { Pemerintah } \\
\text { Kota } \\
\text { Pekanbaru } \\
\text { Nurnasrina, } \\
\text { 2014) }\end{array}$ \\
\hline $\begin{array}{l}\text { Jurnal } \\
\text { Internasion } \\
\text { al }\end{array}$ & $\begin{array}{l}\text { Public } \\
\text { Perception Of } \\
\text { Biofuel Usage } \\
\text { In Vietnam } \\
\text { (Chaiyapa } \\
\text { et.all., 2018) }\end{array}$ & $\begin{array}{l}\text { Perception Of } \\
\text { "Publicness" Of } \\
\text { The Public Spaces } \\
\text { With Special } \\
\text { Reference To } \\
\text { Public Parks In } \\
\text { Colombo And Sri } \\
\text { Jayewardenapura } \\
\text { (Bandara et. All., } \\
\text { 2013). }\end{array}$ & $\begin{array}{l}\text { Public } \\
\text { Perception Of } \\
\text { Environment } \\
\text { al Risk In } \\
\text { Turkey (Bilgin } \\
\text { \& Sanin, } \\
2017 \text { ) }\end{array}$ & $\begin{array}{l}\text { Public } \\
\text { Perception } \\
\text { on Cashless } \\
\text { Transactions } \\
\text { in India } \\
\text { (Podile \&v } \\
\text { Rajesh, 2017) }\end{array}$ \\
\hline
\end{tabular}

Sumber: di olah dari berbagai sumber

Berdasarkan penelitian terdahulu yang dipaparkan peneliti pada tabel diatas bahwa belum adanya penelitian yang mengkaji tentang perubahan persepsi menggunakan jenis penelitian kualitatif yang terfokus pada tokoh agama, dominan penelitian-penelitian sebelumnya yang meneliti persepsi menggunakan jenis penelitian kuantitatif dan bukan terfokus pada persepsi masyarakat kepada tokohnya tetapi pada kebijakan yang dibuat tokoh tersebut ataupun kinerja dari tokoh tersebut dan tokoh yang digunakan adalah tokoh politik.

Dalam melakukan penelitian ini, peneliti menggunakan metode penelitian studi kasus untuk melacak peristiwa-peristiwa kontemporer, apabila peristiwaperistiwa yang bersangkutan tidak dapat dimanipulasi (Yin, 2015:5). Studi kasus yang digunakan dalam penelitian ini adalah deskriptif, dimana peneliti gunakan untuk mendeskripsikan kejadian suatu fenomena atau jika berkenaan dengan 
memprediksi hasil-hasil tertentu. Tujuan dalam penelitian ini sesuai dengan latar belakang yang telah peneliti paparkan sebelumnya adalah untuk mengetahui perubahan persepsi jamaah dakwah ustadz Evie Effendi di Kota Bandung, sehingga peneliti berharap dengan adanya penelitian ini dapat memberikan referensi baru bagi peneliti-peneliti selanjutnya yang akan melakukan penelitian terkait perubahan persepsi dengan jenis penelitian kualitatif. Selain itu, penelitian ini juga diharapkan dapat memberikan manfaat bagi perkembangan penelitian Ilmu Komunikasi, khususnya yang akan meneliti mengenai analisis perubahan persepsi masyarakat terkait suatu fenomena pada tokoh agama.

\section{HASIL DAN PEMBAHASAN}

Berdasarkan hasil wawancara dengan informan, peneliti dapat memaparkan dan menganalisis segala bentuk data yang didapatkan pada saat wawancara mengenai perubahan persepsi jamaah dakwah ustadz Evie Effendi di Kota Bandung terkait ustadz Evie Effendi dan kasus "salah tafsir" beliau. Analisis dilakukan sesuai dengan teori utama yang digunakan yaitu teori persepsi, yang dimana persepsi ditentukan oleh tiga faktor yaitu perhatian (atensi), faktor-faktor fungsional yang menentukan persepsi dan faktor-faktor struktural yang menentukan persepsi. Perhatian (atensi) sendiri terbagi menjadi dua, yaitu faktor eksternal penarik perhatian dan faktor internal penaruh perhatian (Rakhmat, 2011:50).

\section{Faktor Eksternal Penarik Perhatian}

Faktor ini disebut juga faktor-faktor situasional, dimana suatu stimulus diperhatikan karena memiliki sifat-sifat yang menonjol seperti gerakan, intensitas stimuli, kebaruan (novelty) dan perulangan. Dalam faktor ini berdasarkan hasil wawancara yang telah dilakukan, peneliti menemukan bahwa perhatian jamaah dakwah ustadz Evie Effendi tertuju pada banyolan yang disisipkan ketika usatdz Evie berceramah. Banyolan yang mengundang gelak tawa dari jamaah lebih dominan dibandingkan materi yang diberikan. Empat informan yaitu $\mathrm{Hj}$. Dewi Mayangsari, S.E, Rahmat Kurnia, Abdul Farid Alghifari, Rika Abdul Hakim Effendi dan Lisna Auliana mengatakan bahwa penggunaan bahasa Sunda kasar yang digunakan ustadz Evie Effendi ketika berceramah dan bercanda menarik perhatian jamaah khususnya anak-anak muda di Kota Bandung. Salah satu informan yaitu Deden Sirojudin mengatakan materi yang dibawakan ustadz Evie Effendi selalu sama. Selain itu, cara berpenampilan ustadz Evie Effendi juga menarik perhatian jamaah dakwah beliau, karena gaya berbusana ustadz Evie Effendi unik dan berbeda dari ustadz-ustadz lainnya, yakni mengenakan kemeja, topi kupluk, celana jeans dan kaos. Hal-hal tersebut menunjukkan bahwa 
perhatian jamaah cenderung tertuju pada intensitas stimuli yang ditunjukkan dari canda tawa dan penggunaan bahasa sunda kasar serta kebaruan (novelty) yang ditunjukkan dari cara berpakaian ustadz Evie Effendi yang berbeda dari ustadzustadz lainnya.

\section{Faktor Internal Penaruh Perhatian}

Faktor ini juga disebut sebagai faktor personal yang melihat bahwa faktor-faktor biologis, faktor-faktor sosiopsikologis, motif sosiogenis, sikap, kebiasaan dan kemauan mempengaruhi apa yang manusia perhatikan sehingga apa yang menjadi perhatian kita belum tentu menjadi perhatian orang lain maupun sebaliknya. Dalam bagian ini, peneliti menemukan beberapa informan yang memperhatikan ustadz Evie Effendi dari sisi kemauan, diantaranya yaitu Rika yang mengikuti ustadz Evie Effendi di Instagram dan mencari informasi kajiankajian ustadz Evie melalui posting-an ustadz Evie di Instagram. Rika tertarik dengan ustadz Evie Effendi dan ingin sekali ikut kajian ustadz Evie. Selain itu juga Abdul Farid Alghifari yang memperhatikan ustadz Evie Effendi dari sisi kebutuhan akan materi yang diberikan oleh ustadz Evie Effendi, dimana Abdul Farid Alghifari masih ingin mengikuti kajian ustadz Evie Effendi walaupun setelah terjadinya kasus "salah tafsir" karena Farid masih membutuhkan ilmu, yang dimana menurut Abdul Farid Alghifari ilmu bisa di dapat darimana saja dan dari siapa saja. Dari pemaparan jawaban informan tersebut dapat terlihat bahwa kemauan dan motif sosiogenis menentukan apa yang menjadi perhatian oleh masyarakat khususnya jamaah dakwah ustadz Evie Effendi di Kota Bandung.

\section{Faktor-Faktor Fungsional yang Menentukan Persepsi}

Faktor-faktor fungsional sendiri berasal dari kebutuhan, pengalaman masa lalu dan hal-hal lainnya yang disebut sebagai faktor personal. Dalam hal ini yang menentukan persepsi bukan stimuli namun karakteristik orang yang memberikan respon pada stimuli tersebut. Krech dan Crutchfield dalam Mulyana (2017:55) mengungkapkan bahwa pengaruh kebutuhan, kesiapan mental, suasana emosional dan latar belakang budaya mempengaruhi persepsi yang diberikan. Ustadz Evie Effendi dilihat dari materi yang dibawakan ketika ceramah terlalu ringan sehingga tidak memberikan penambahan ilmu yang cukup karena materi yang diberikan ustadz Evie Effendi sudah pernah di dapatkan dari ustadz-ustadz lainnya yang pernah diikuti. Setelah terjadinya kasus "salah tafsir" yang menjerat ustadz Evie Effendi saya semakin tidak mau mengikuti, ucap Hj. Dewi Mayangsari, S.E. Hal yang serupa juga dirasakan oleh Abdul Farid Alghifari yang merasa setelah adanya kasus "salah tafsir" ketertarikannya terhadap ustadz Evie Effendi berkurang. Berbeda dengan Deden Sirojudin yang merasa biasa saja pada ustadz Evie Effendi karena menurutnya ustadz Evie Effendi tanpa ada 
kasus "salah tafsir" pun tetap akan ditinggalkan jika materi dan cara penyampaiannya tetap monoton dan tidak ada variasi. Hal berlainan dikatakan oleh Rika Abdul Hakim Effendi dan Lisna Auliana yang memaklumi dan memaafkan ustadz Evie Effendi tekait kasus "salah tafsir" yang menurutnya hal yang wajar melihat latar belakang pendidikan dan kehidupan ustadz Evie Effendi yang memang tidak pernah menempuh pendidikan pesantren sebelum menjadi ustadz. Pandangan yang diberikan informan kepada ustadz Evie Effendi dan kasus "salah tafsir" beliau pada bagian ini terlihat bahwa pengalaman dan kebutuhan yang mendominasi alasan jamaah dakwah ustadz Evie Effendi mempersepsi ustadz Evie Effendi.

\section{Faktor-Faktor Struktural yang Menentukan Persepsi}

Faktor-faktor struktural penentu persepsi melalui teori Gestalt yang dikemukakan oleh para psikolog Gestalt, seperti Kohler, Wartheimer (1959) dan Koffka yang mengatakan apabila ingin memersepsi sesuatu, kita harus memersepsinya sebagai suatu keseluruhan yang dalam hal ini konteks menentukan makna. Selain itu stimuli juga dipandang oleh manusia dari strukturnya, sehingga manusia mencoba mencari struktur dalam rangkaian stimulinya yang di dapat melalui pengelompokkan berdasarkan kedekata atau persamaan. Dalam hal ini ustadz Evie Effendi yang dinilai oleh jamaah dakwahnya sebagai ustadz kekinian menurut Abdul Farid Alghifari sudah banyak ustadz-ustadz kekinian lainnya seperti beliau diantaranya ustadz Hanan Attaki dan ustadz Adi Hidayat. Deden Sirojudin juga mengatakan bahwa pelapor kasus "salah tafsir" ustadz Evie Effendi menurutnya cenderung lebih politis dan tidak konsisten dalam membela Islam karena hanya membesar-besarkan kasus ustadz Evie saja tapi tidak ikut berpartisipasi dalam aksi-aksi bela Islam lainnya seperti aksi 212 dan aksi bela tauhid. Dari sisi yang berbeda juga dilihat oleh Hj. Dewi Mayangsari, S.E yang menurutnya kasus ustadz Evie Effendi serupa dengan kasus Aa Gym dahulu yang sama-sama terkena ketika sedang berada di puncak kejayaan karirnya dan memberikan dampak pada lingkungan sekitar yang cukup besar. Kemudian ustadz Evie Effendi dalam hal ini merupakan seorang publik figur yang dinilai Rika akan lebih sukses setelah terkena kasus "salah tafsir" serupa dengan Ariel Peterpan yang juga seorang publik figur dan setelah terkena kasus jauh lebih sukses dari sebelum terkena kasus. Hal-hal tersebut yang telah dipaparkan oleh jamaah dakwah ustadz Evie Effendi sebelumnya merupakan pandangan dari setiap jamaah yang dominan melihat ustadz Evie Effendi baik dari kasus "salah tafsir" maupun kasus-kasus serupa lainnya dari sisi strukturnya yaitu adanya kesamaan atau kedekatan.

Persepsi yang diberikan informan yakni jamaah dakwah ustadz Evie Effendi di Kota Bandung diatas, merupakan tahap dimana proses yang diawali 
dengan objek menghasilkan stimulus, kemudian stimulus mengenai alat indera dan diteruskan ke saraf sensoris ke otak yang selanjutnya di otak terjadi proses psikologis dimana proses individu menyadari apa yang dilihat, didengar maupun dirasakan oleh indera kemudian menghasilkan persepsi. Respon sebagai efek dari persepsi dapat diambil oleh individu dalam berbagai macam bentuk. Stimulus yang datang dari lingkungan tidak hanya satu, namun ada beberapa maka dari itu perlu adanya perhatian sebagai langkah dalam persepsi karena tidak semua stimulus mendapatkan respon dari individu untuk dipersepsi.

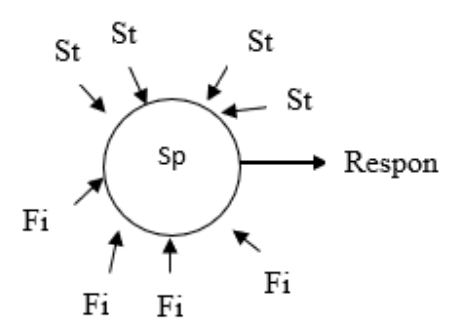

Sumber: Bimo Walgito "Pengantar Psikologi Umum"

\section{Gambar 1. Proses Terjadinya Persepsi}

Keterangan :

St $\quad$ : Stimulus (Faktor Luar)

Fi : Faktor intern (faktor dalam termasuk perhatian)

Sp : : Struktur pribadi individu

Gambar diatas menunjukkan bahwa stimulus yang terdapat pada ustadz Evie Effendi bermacam-macam namun hanya beberapa stimulus yang diterima dan mengenai alat indera. Stimulus yang diterima adalah stimulus yang dianggap paling menonjol atau yang sesuai dengan apa yang dibutuhkan oleh jamaah dakwah ustadz Evie Effendi. Dari sekian banyak stimulus, hanya satu stimulus saja yang menonjol dan menarik perhatian jamaah dakwah ustadz Evie Effendi untuk kemudian stimulus tersebut di interpretasikan dan di respon dalam bentuk persepsi.

\section{Analisis}

Berdasarkan pemaparan peneliti pada hasil penelitian, terdapat persamaan alasan yang penulis dapatkan dari empat informan yakni ketertarikan informan terhadap ustadz Evie Effendi tertuju pada banyolan yang ustadz Evie sisipkan di 
tengah materi ceramah yang ia bawakan terlebih menggunakan bahasa Sunda kasar yang disukai oleh jamaah ustadz Evie Effendi khususnya anak-anak muda di Kota Bandung. Selain itu perhatian jamaah dakwah ustadz Evie Effendi juga tertuju pada materi yang diberikan karena jamaah masih membutuhkan ilmu dari ustadz Evie Effendi dan senang dengan ustadz Evie hingga mengikuti ustadz Evie Effendi di media sosial Instagram untuk mengikuti perkembangan informasi kajian ustadz Evie Effendi.

Ustadz Evie Effendi dianggap oleh sebagian informan sebagai ustadz yang ilmunya belum terlalu mumpuni, hal tersebut ditunjukkan dari materi yang diberikan ustadz Evie Effendi terlalu ringan, selalu diulang ketika ceramah dan tidak memberikan penambahan ilmu, terlebih setelah terjadinya kasus "salah tafsir" yang membuat sebagian informan merasa semakin yakin untuk tidak mengikuti kembali kajian ustadz Evie Effendi. Namun sebagian informan lainnya mengungkapkan rasa simpatinya kepada ustadz Evie Effendi setelah adanya kasus "salah tafsir" karena mengetahui latar belakang kehidupan dan pendidikan ustadz Evie sehingga sebagian informan tersebut memaklumi dan memaafkan ustadz Evie Effendi terkait kasus "salah tafsir" karena ustadz Evie Effendi juga sudah meminta maaf dan melakukan klarifikasi di official Youtube beliau. Hal tersebut menurut pakar psikologi komunikasi yaitu Dr. Hj. Jenny Ratna Suminar, Dra., M.Si terjadi karena kultur masyarakat Indonesia yang permisif yaitu cepat memaafkan dan melupakan sehingga persepsi negatif masyarakat khususnya jamaah dakwah ustadz Evie bersifat sementara yaitu dari bulan Agustus sampai Desember 2018.

\section{PENUTUP}

Berdasarkan seluruh hasil penelitian dan pembahasan yang telah peneliti uraikan, peneliti dapat menarik kesimpulan bahwa terdapat perubahan persepsi pada jamaah dakwah ustadz Evie Effendi di Kota Bandung namun memiliki perbedaan persepsi bagi rentang usia 40 - 50 tahun dan usia 20 tahun. Untuk jamaah usia 40 tahun sampai 50 tahun semakin meragukan ilmu yang dimiliki ustadz Evie Effendi karena sebelumnya pada saat mengikuti kajian merasa materi yang diberikan ringan yang kemudian dibuktikan dengan adanya kasus "salah tafsir" yang menjerat ustadz Evie Effendi yang semakin meyakinkan untuk tidak mengikuti kembali kajian ustadz Evie. Sedangkan untuk usia 20 tahun, perubahan persepsi yang terjadi pada jamaah yaitu lebih memaklumi dan memaadkan ustadz Evie Effendi terkait kasus "salah tafsir" yang menjerat beliau dan beberapa diantara jamaah lebih simpati karena mengetahui latar belakang kehidupan ustadz Evie Effendi.

Pemakluman terhadap ustadz Evie Effendi dan kasus "salah tafsir" terjadi 
karena kultur masyarakat Indonesia yang permisif sehingga dalam jangka waktu 4 bulan saja dari pelaporan kasus "salah tafsir" ustadz Evie Effendi pada bulan Agustus 2018, persepsi masyarakat berubah yang sebelumnya pada saat kasus sedang naik di media sosial dan menjadi perbincangan hingga perdebatan masyarakat khususnya jamaah dakwah ustadz Evie Effendi kini berubah menjadi redup seolah-olah kasus tersebut tidak pernah terjadi.

Adapun peneliti merasa perlu untuk memberikan saran karena peneliti menyadari masih terdapat banyak kekurangan dalam penelitian ini, diantaranya peneliti berharap agar kedepannya lebih banyak penelitian yang mengkaji bidang psikologi komunikasi khususnya persepsi. Selain itu, peneliti juga berharap agar tutur bahasa dan materi yang diberikan ustadz Evie Effendi lebih menyesuaikan dengan karakteristik jamaah yang hadir mengikuti kegiatan ceramah dengan tujuan untuk meminimalisir kesalahan pemahaman. Peneliti juga berharap agar jamaah dalam memberikan persepsi terkait pemberitaan suatu kasus sebaiknya melakukan klarifikasi terlebih dahulu dengan tujuan agar tidak terkena berita bohong (hoax) dan tidak terjadi kesalahan persepsi yang berujung fitnah.

\section{DAFTAR PUSTAKA}

Adib, S. (2017). Persepsi Calon Jamaah Haji Terhadap Akad dalam Dana Setoran Awal Pelaksanaan Haji (Studi Kasus Kementerian Agama Kota Banjarmasin). Skripsi, Jurusan Ekonomi Syariah, UIN Antasari, Banjarmasin.

Azis, F. (2016). Persepsi Masyarakat Tentang Aktualitas Informasi Berita di TV One (Studi Pada Masyarakat Allattappampang Kecamatan Pallangga Kabupaten Gowa). Skripsi, Jurusan Ilmu Komunikasi, UIN Alauddin, Makassar.

Bandara et. All (2013). Perception of "Publicness" of The Public Spaces with Special Reference to Public Parks in Colombo and Sri Jayewardenapura. ISVS e-journal, 1(1).

Bilgin, A. \& Sanin, L.S. (2017). Public Perception Of Environmental Risk In Turkey in Fresenius Environmental. Bulletin, 26(12A), 8093-8099.

Chaiyapa et. All. (2018). Public perception of biofuel usage in Vietnam. Biofuels,1-13.

Fatkhiyyah, A. (2017). Persepsi Jamaah Terhadap Penggunaan Parabahasa dan Gerakan Tangan Dalam Dakwah Habib Muhammad Firdaus (Studi Kasus Jamaah Al-Muqorrobin Kendal). Skripsi, Jurusan Komunikasi dan Penyiaran Islam, UIN Walisongo, Semarang. 
Mulyana, D. (2017). Ilmu Komunikasi Suatu Pengantar. Bandung: PT Remaja Rosdakarya.

Nurnasrina (2014). Persepsi Masyarakat Terhadap Kebijakan Ekonomi Pemerintah Kota Pekanbaru dalam Menara Riau: Jurnal Kewirausahaan, (13) 1, 61-71.

Pambudi, K.S. (2017). Penelitian Studi Kasus Fenomenologi Persepsi Keadilan Pelaku Pembunuhan Anggota PKI 1965 dalam Jurnal Sains Psikologi, 6 (1) 22-30.

Podile, V. \& Rajesh, P. (2017). Public Perception on Cashless Transactions in India. Asian Journal of Research in Banking and Finance , 7(7), 63-77.

Prasetyo, D. (2014). Persepsi Masyarakat DKI Jakarta Terhadap Figur dan Komunikasi Politik Basuki Tjahaja Purnama (AHOK) dalam POLITIKA, (5) 2 .

Rakhmat, J. (2011). Psikologi Komunikasi, Bandung: PT Remaja Rosdakarya.

Rosidin (2018). Persepsi Jamaah Terhadap Pemberdayaan oleh Takmir Masjid di Kota Madiun Jawa Timur dalam INFERENSI Jurnal Penelitian Sosial Keagamaan, (12)1, 177-194.

Sailan, M.A.B. (2017). Persepsi Mahasiswa IMARAH Terhadap Dakwah Ustadz Azhar Idrus di Media Youtube. Skripsi, Jurusan Komunikasi Penyiaran Islam, UIN Raden Fatah, Palembang.

Yin, R. K. (2015). Studi Kasus: Desain dan Metode. Jakarta: PT Rajagrafindo Persada. 